\title{
Facilitation fundamentals: redesigning an online course using adult learning principles and trifecta of student engagement framework
}

\author{
Heather J. Leslie \\ Learning Design Center, University of San Diego, San Diego, California, USA
}

\begin{abstract}
Purpose - The purpose was to describe the redesigning of an online course that utilized adult learning principles and a framework to engage students.

Design/methodology/approach - The methodology used is a first person account from the instructor point of view.

Findings - Findings indicate that the teaching strategies used encouraged student engagement in the course. Research limitations/implications - The research is limited to one course with less than 20 students. Practical implications - Other online instructors can utilize teaching strategies used that promote engagement among students.

Social implications - This course is an example of a highly engaging online course. This shows that online courses can be engaging and satisfying for students.

Originality/value - This paper adds to the body of literature on what teaching strategies encourage students to engage online. It connects theories with real life examples that others teaching online can implement.

Keywords Adult learning, Course design, Student engagement, Active learning, Online teaching, Facilitation Paper type Conceptual paper
\end{abstract}

\section{Introduction}

I was invited to teach and redesign an online course in the Advanced Dispute Resolution (ADR) program called ADR410: facilitation fundamentals. The professor who teaches this course has many years of successful experience teaching this course in an onsite classroom but has had challenges in transitioning the learning experience to an online format. ADR410 is an upper division undergraduate course for students across a range of disciplines including business administration, organizational leadership, paralegal studies, prelaw, homeland security and criminal justice. The ADR program is a minor program and certificate at National University (NU). Courses at NU are four weeks long to appeal to adult learners who prefer fast-paced degree programs.

Students enrolled in the course are nearing the end of their studies and are nontraditional adult learners between the ages of 25 and 45 who are working professionals and tend to have family and commitments on top of school. Many serve in the military or are veterans and come from diverse backgrounds and cultures. Because a majority of students taking this course are close to finishing their degree programs, the retention rate is high, the dropout rate

(C) Heather J. Leslie. Published in Journal of Research in Innovative Teaching \& Learning. Published by Emerald Publishing Limited. This article is published under the Creative Commons Attribution (CC BY 4.0) licence. Anyone may reproduce, distribute, translate and create derivative works of this article (for both commercial and non-commercial purposes), subject to full attribution to the original publication and authors. The full terms of this licence may be seen at http://creativecommons.org/licences/by/4.0/ legalcode

Redesigning an online course

Received 2 September 2019 Revised 24 November 2019 Accepted 6 March 2020 
JRIT

14,2 is low and the motivation to finish and graduate is high. Students in this program are adult learners who come with varying professional backgrounds, education, and life experience. Effective methods for teaching adults tend to use constructivist approaches where learners connect new knowledge to existing knowledge to make meaning of that knowledge (Lord, 1999; Merriam and Bierema, 2014). Because adult learners bring a wealth of experience and knowledge to class, they are engaged by opportunities to participate and share their knowledge and experience and connect it to class topics and concepts (Allen, 2016; Johnson and Stage, 2018; King, 1993; National Institute of Education, 1984; Ross-Gordon, 2011).

Because students in this course are adult learners, this course was redesigned using learner-centered approaches that fit adult students as follows: practical skills and knowledge they can immediately apply, active learning strategies to encourage participation and involvement in learning, choice and freedom in choosing learning paths, constructivist and humanistic methods to make meaning and create community, authentic assessments to evaluate practical knowledge and skill acquisition as well as critical thinking and modeling facilitation as a teaching strategy. The design of the course and strategies used to teach this course are grounded in adult learning principles and a framework referred to as the trifecta student engagement.

\section{Trifecta of student engagement framework used for course design}

In addition to adult learning principles, the framework used to redesign this course was based on a framework that was developed by Michael G. Moore in 1989. This framework, referred to as the trifecta of engagement, represents three types of interaction that need to occur in an online course to be considered learner-centered. Moore (1989) labels these as learner-content interaction, learner-learner interaction and learner-instructor interaction. Therefore, the trifecta of student engagement posits that students need to regularly and meaningfully interact with their course curriculum content with their peers and with their instructor to be fully engaged in a course.

In each week, students engage with a variety of course content, engage with their peers and engage with their instructor. To engage students with course content, content was presented in different formats such as text-based readings, video lessons and interactive presentations to appeal to different learning preferences and modalities. Including variety in visual, auditory and kinesthetic elements can make content more engaging for students (Choi and Johnson, 2005; Brame, 2016; The National Center on Universal Design for Learning, n.d.). To engage students with their peers, students did threaded discussions, synchronous collaborate sessions and a peer evaluation. To engage students with me, I interacted with students in threaded discussions, synchronous collaborate sessions, one-on-one email and phone communications, webcam announcements, video lessons, instructional videos and feedback received on assignments.

Some of the learning objectives in the course were changed from lower-order to higherorder levels. Undergraduate courses tend to use lower levels of Bloom's taxonomy (Momsen, 2010). But as lower-order thinking tasks such as memorization and rote learning become automated by machines in the not-too-distant future, today's learners require competencies in complex cognition and higher-order thinking to prepare for work in ever-changing environments that call for creativity, collaboration, innovation and solutions to novel problems (van Merrienboer, 2001). In addition, because the students in this course are adult learners with developed critical thinking skills, advancing the levels to higher order thinking was viewed as appropriate. Finally, the topic of this course is facilitation fundamentals, and yet students were not expected to facilitate anything in previous versions of the course. Rather they were expected to discuss, identify, describe, recognize, know and understand aspects of facilitation. Equipping students with tools, strategies, knowledge and skills in 
facilitation can allow them to engage their peers in course concepts that utilize higher-order thinking and peer-to-peer teaching and learning (Rekrut, 1994; Odena and Burgess, 2017). Facilitation skills also fall under social and emotional skills needed to guide change and make progress (OECD, 2015). To provide students with practical skills and knowledge in facilitation, I decided to incorporate learning objectives that required students to actually facilitate.

The following learning outcomes were added to the course to provide students with practical skills and knowledge in facilitation:

(1) Develop question techniques and communication strategies to facilitate discussion among participants.

(2) Facilitate an interactive online asynchronous discussion using questioning techniques and engaging communication style.

(3) Facilitate an interactive online synchronous session with peers using questioning techniques and engaging communication style.

(4) Evaluate facilitation session and provide substantive feedback using assessment criteria.

Previously, this course had a quiz on the course outline in week one. I redesigned week one to have students discuss a learning objective in the course that they are most interested and why in the "Introduce Yourself" discussion board instead of a quiz in order to allow students to review the course and form an intrinsic connection to the learning objectives. This utilizes a constructivist approach to having students make meaning from the content and apply it to what they are interested in as well as connect it to what they already know (Merriam and Bierema, 2014). I created a welcome video to discuss the course outline in detail and provide students with expectations for the course, an orientation to the various assignments and activities, what they can expect from me and how they can contact me. At the beginning of every week, I sent out a webcam video announcement to add my instructor presence (Garrison, 2000) to the course and let students know what they have to do that week.

\section{Introducing and welcoming students to the course}

Most online courses at National University have a discussion board for students to post introductions. In the "Introduce Yourself" discussion board, I had students share their advice for succeeding in online courses, which can be powerful coming from peers. It is important to set the tone for the course, by creating a welcoming, engaging and inclusive introduction and orientation to the course (Iowa State University, n.d.). One way to create a welcoming class environment is through ice breakers which allow students to get to know each other and the instructor (Open2Study, 2013). As an ice breaker, I had students share their favorite food and a food they cannot stand. It is amazing the comraderie that can develop over a mutual love of pizza or a mutual distaste for mushrooms. Students were encouraged to do a webcam introduction to humanize themselves to their peers and earn one extra credit point. Three students did webcam introductions. I also did a webcam introduction to model this for students. For students who did a webcam introduction, I replied using webcam. I responded to all student posts to welcome each and every student to the course and engage with them.

I developed some formative assessments to measure if the learning objectives were met via an activity in the live collaborate session. This course has synchronous live sessions via Blackboard Collaborate Ultra once a week. These sessions tend to follow the format of the instructor giving a live lecture while the students listen and occasionally use the chat feature 
JRIT

14,2

to communicate. But, often times, students can be tempted to not pay close attention and it can be difficult to determine if the students are learning if they are not actively participating. I decided to flip the live sessions by having students come prepared to answer questions and participate. We did activities where students were broken up into groups of three to four and had to answer questions based from the readings. They also had to provide an example to support or illustrate their answer.

To prepare students for attending the live session, I created a nongraded video quiz, using Kaltura video software. This video quiz gave students an opportunity to test their understanding of the material and engage a little deeper by asking them to recall what they just learned (Hendel-Giller et al., 2010). Because this video quiz had students actively answer questions, it could be considered an active learning activity, appealing to kinesthetic, visual and auditory learning preferences (Onchengo, 2013). While in the synchronous session, students were oriented to the tools available in the collaborate ultra platform (chat, microphone, webcam, white board, poll) and the different ways to participate in an exercise I facilitated called "Learning How to Learn Online." Students had to compare and contrast their role as learners in the face-to-face classroom versus the online classroom and share ideas about how they can create an effective learning environment for themselves and be successful online learners. Students were made aware of the expectations for their participation (ground rules) and how to contribute to the learning community to get the most out of the experience. This exercise prepared students to participate effectively in the live synchronous sessions. At the end of each session, students were asked to fill out an exit ticket where they answered the prompts: Things I learned today ... Things I found interesting ... Questions I still have ... General feedback on the course/session. The answers students provide help the instructors guide the learning experience and make any adjustments to the course (Rushton, 2005). It also helps differentiate instruction. For example, one student said that she was struggling to grasp the details about the process and methods; so I reached out to her to talk one-on-one and clarify any confusion she had.

Student comments from the exit tickets indicated that most enjoyed the interactive style of the session. Two students said, "Great interactive course!" Another student said, "One of my favorite sessions because of the high level of interactivity." Another student said, "Very interesting way to get students engaged and participating in an online course." And another student said, "I enjoyed our initial session. [The] professor created an environment that was welcoming, interactive and fun."

The other formative assessment in week one was a nongraded facilitation practice discussion board where students practiced their facilitation skills by coming up with a "hot topic" question or prompt and tried to keep the conversation going as long as possible using the Socratic questioning technique. Students needed to ask an interesting, open-ended question and accept every response offered by peers to ensure that the offering of the student is not seen as "wrong," "pointless," or "irrelevant" by the student or other students in the course. They also need to end any replies with a question to stimulate further discussion. This low-stakes practice activity introduces students to the Socratic method of asking questions. The use of Socratic questioning can be a strategy to enhance students' critical thinking (Gokhale and Machina, 2018). Because this was an informal activity as opposed to a formal academic writing assignment, the students were more authentic in the way they posed questions and answered their peers. Overall, I was very impressed with the questions students asked and the way they responded to their peers. Some of the hot topics students came up with included arming teachers, wealth inequality, gun control laws, violent video games, immigration and family separation, the welfare system, women in military combat roles, children of divorce and dating, and marijuana legalization. These topics all have the potential to result in heated debate, but the students were respectful and exhibited higherorder thinking and intellectual reflection on complex topics. If students forgot to ask a 
question at the end of their reply, I would nudge them via email and remind them to end their reply with a question so they could keep the conversation going. This practice discussion board prepared students for a summative assessment in which they had to facilitate an

\section{Giving students choice and freedom in learning}

Giving learners choice and freedom to make decisions in how they demonstrate their learning allows them to be more self-directed, autonomous learners and take responsibility for their online course learning (Butler and McMunn, 2011; Merriam and Bierema, 2014; Rashid and Asghar, 2016). In week one, students sign up for a facilitation topic from a list of topics from the textbook, The Skilled Facilitator. Students facilitate discussions, asynchronously and synchronously, on their topic in weeks three and four. Students sign up for a day and time to facilitate their synchronous session in week four. This allows students to plan ahead by marking their calendars and begin researching their topic. I coordinated the days and times students would facilitate their synchronous sessions in week four and sent them all calendar invites to block off the times they would be facilitating.

\section{Giving students practical skills and knowledge}

Instead of doing a midterm research paper where students write about facilitation topics, as the course previously required, I had students facilitate discussions (in weeks three and four) both asynchronously and synchronously with their peers to give them practical skills in facilitation. Adult students appreciate the acquisition of practical skills and knowledge that they can use in work and in their personal lives (Knowles, 2005). Having students apply knowledge and skills in a real-life context is known as authentic learning (Davidson et al., 2019). Today's technological environment also requires practical skills in digital competencies such as online discussion and webinar facilitation (Leslie and McCarty, 2018).

In week two, students engaged in a threaded discussion about a situation in which they had to prepare to facilitate a community forum. They had to discuss how they, as the facilitator, would work to create group effectiveness, address group behavior, establish ground rules and intervene if a conflict broke out. Instruction included the readings on group effectiveness model, group behavior, ground rules and diagnosis intervention. Instruction also included a video lecture on group dynamics and a case study on the process of facilitating a community forum. Content was presented in multiple formats (text and video) to appeal to diverse learner preferences. Students have different learning preferences such as auditory, kinesthetic, visual (or combination) (Onchengo, 2013). Therefore, presenting content in different formats can engage different types of learners.

\section{Flipping the classroom to promote active learning}

In week two, I developed a formative assessment for students by creating an interactive collaborate live session where students were asked questions to test their understanding using the tools available in Blackboard Collaborate Ultra such as the poll, chat and white board. Students were called on to verbally expand on their answers typed in the chat to further the depth of interaction and participation, which also modeled facilitation practices. Students were informed that they would need to come to the session familiarized with the concepts in the chapter readings and be ready to participate. This flipped style session allowed students to explain what they learned and be engaged in the session through participation activities.

A flipped classroom setting encourages active learning (Sturek, 2015). Students learn more when they actively create information during learning such as summarizing a passage 
JRIT

14,2

after reading it. Conversely, students who use passive methods such as reading a text or listening to a lecture without taking notes do not retain as much (Benassi et al., 2014). Therefore, a flipped classroom that uses active learning invites students to contribute by asking them to recall what they learned, engage in discussion and participate in activities to make meaning of the content.

Once again, students were asked to complete an exit ticket after the session, and the student comments indicated that they found the session to be interactive and engaging. One student comment said: "I love that the course is interactive. It challenges you to remain attentive and engaged, and, as a result I learn a lot. It also helps me to stay awake during class." Another student said, "I like how the professors keep engaging the class to be active." Another student said, "I greatly enjoy this class and level of interaction and the practical application."

\section{Making content relevant to students}

At one point in the synchronous session, a student mixed up the concepts of espoused theory and theory in use. I thanked the student for his willingness to participate even if he did not get the answer right because, surely, he is not alone, and other peers were likely mixed up as well. We assured the class that being in a learning community means you may not always know the right answer and that is ok as we are all learning together. One observation I have is that adult learners tend to be more willing to participate, even if they risk being wrong, than other younger, traditional-aged college students. Perhaps this comes with maturity and a greater desire to learn the material if it is relevant to them.

Speaking of relevance, Malcom Knowles' (2005) principles of adult learning indicate that adults are interested in learning subjects that have immediate relevance and impact to their job or personal life. In week one, students introduced themselves in an "Introduce Yourself" discussion board where they also were asked to identify a learning outcome in the course that is most important to them and why. This allowed them to connect the course to their own life to provide relevancy. When I responded to students, I made suggestions on facilitation topics they may want to research based on their interest for their facilitation activities in weeks three and four. This also utilizes a constructivist approach that allows students to make meaning of the course content by connecting it to their own experience (Merriam and Bierema, 2014). Part of engaging students with content entails making content relevant to them.

\section{Incorporating problem-based learning}

Another principle of adult learning is that adult learning is problem-centered rather than content-, subject- or discipline-oriented (Knowles, 2005). Therefore, problem-based learning (PBL) tends to work well for adult learners (Barrows, 1996). In week two, students participate in a realistic scenario discussion board where they are tasked with planning and facilitating a forum in a community that has just underwent a police shooting and protests have erupted in the community. This activity is both a summative assessment that allows students to demonstrate their knowledge of facilitation practices and a formative learning event that allows students to engage in a critical thinking discussion with their peers using the Socratic questioning technique, which they practiced in week one.

\section{Humanizing the discussion board}

Students were advised that they were not required to use formal academic language but rather that they could "keep it real" and write how they would speak (informal, but professional). I told them, "No need to sound like a research paper. Be yourself!" 
Online discussions typically require proper academic writing, grammar, spelling and formatted citations (Barstow Community College, n.d.). When discussions entail formal academic writing, students rarely dive deeper into the conversation or topic and many just do the bare minimum of responding to two of their peers if it is required (Bart, 2018). But Schmidt challenges the practice of discussions used as a space for formal academic writing and instead advocates for a more humanistic approach to the discussion board. Rather than using formal academic writing such as that used in a paper, Schmidt (2017) advocates using authentic language when engaging in online discussions (e.g. write how you would talk) as this

usher[s] learner motivation ... prepares the learner most effectively to transfer their developing language skills to the outside world ... motivates a learner to know that what they are engaging in will be directly applicable to real life as soon as they walk out of the classroom ... [and] creates a sense of community among students who are collectively engaged in the construction of meaning (para. 3).

Therefore, I wanted students to use language that is more natural to them while still probing for understanding and asking them to demonstrate critical thinking related to the topic. In my view, this made online discussions much more enjoyable, social, enriching, engaging and not seem like busy work. One student commented in the exit ticket: "Love the concept of "write like you talk". . . be yourself." I encouraged the students to keep the conversation going like they did in the week one facilitation practice discussion board and try to examine the issues from as many points of view as possible to really dissect and analyze the situation for their intellectual development.

I tried to model good facilitation practices by staying active in the discussion board and posing questions to make students think so they could learn from my example and examine the situation from multiple perspectives. I responded to every student post in the discussion board to be visible in the course and engage with every student. After the week two discussion board was complete, I compiled and summarized everyone's ideas into a document and sent it out via an announcement to wrap up the activity. This modeled to students an important aspect of facilitation - summarizing and concluding what was said in a discussion.

\section{Videos to enhance teaching}

To prepare students for participating and facilitating, I created a video lesson in week two on the art and science of asking questions which included information on the Socratic method and different types of questions to ask. I used a video to present this content because videos can be engaging for learners (Hibbert, 2014). Hibbert (2014) states that "Video has the ability to convey material through auditory and visual channels, creating a multisensory environment" (para. 2). Videos can convey instructor presence and add a human element. In addition to video lessons, I frequently sent out webcam video announcements to add my instructor presence to the course. Videos can be an effective way to demonstrate a procedure, explain a detailed method or bring a process or idea to life using 3-D images, audio and graphics. Choi and Johnson (2005) found that the use of instructional videos can be used to motivate learners by attracting their attention and can help with comprehension and retention of information through the use of visual and audio aids (Choi and Johnson, 2005). I embed instructional videos in the instruction area of every assignment in Blackboard in order to verbally explain instructions to students, demonstrate to them where to navigate in the course, as well provide best practice tips such as subscribing to the discussion boards to stay up to date. Instructional videos are also helpful for showing students examples of good work versus poor work (Brame, 2016). Presenting content in multiple modalities such as video adds variety to appeal to diverse learner preferences such as auditory, visual, kinesthetic or combination (The National Center on Universal Design for Learning, n.d.). 


\section{Rubrics and feedback}

One of the most critical areas where instructors engage with students is through giving feedback (Dennen, 2007). In addition, feedback is a tool that can be used to facilitate learning (Pyke, 2010). Prompt feedback allows learners to examine their current knowledge, reflect on their learning and receive recommendations for improvement. Feedback should be specific, objective, consistent and timely (Sachdeva, 1996). When I graded the week two discussion board, I provided substantive feedback on every category/criterion to clearly describe what the student did well on and where improvement was needed. In addition, I provided overall feedback to summarize where the student excelled and where they needed to improve. To make the feedback timely, I let students know they would have an opportunity to work on these areas in the next facilitation assignment so that they could apply the feedback to immediate future use. I used an embedded rubric in Blackboard to provide feedback. Rubrics can establish clear, consistent criteria and standards to measure student performance (Barkley and Major, 2016). Students were provided rubrics in advance of the assignment and were highlighted in the instructional videos to let students know the criteria that they would be evaluated on.

In week three, students facilitated an asynchronous discussion board using the topic from the textbook they selected in week one. Each student signed up for a different topic. Students were then tasked with being an expert on their topic. This gave students some choice and autonomy in selecting their topic. Adult learners enjoy having choice and freedom to choose learning paths and showcase their learning (The National Center on Universal Design for Learning, n.d.). Students facilitated a discussion by asking a question or posing a prompt to their peers on a topic in which they are the expert because facilitators are experts on content and process (Schwartz, 2002). Asking students to be an expert on the topic will ideally result in students taking more ownership for their learning and be more autonomous, self-directed learners, which adult learners tend to gravitate towards (Merriam and Bierema, 2014).

\section{Encouraging student creativity}

Students were advised to try and draw people into their question or prompt. Their question or prompt should not feel like busy work or a homework assignment for their peers to answer. They should try to connect it to something interesting such as a startling fact, a story or a statistic just like they did in the week one facilitation practice discussion board when they chose a hot topic for discussion and asked their peers their thoughts, opinions, ideas, feelings and reactions. They should try to craft a question, scenario or prompt that hooks the audience and grabs their attention. It was my intention to engage student's different learning preferences by giving them freedom to creatively showcase their learning (The National Center on Universal Design for Learning, n.d.). In a video lesson, I went over the rubric criteria and gave examples of strategies their peers used to reel people into their topics in the week one facilitation practice discussion board such as students who presented a point of view, an interesting or alarming fact or a current event. Some students selected topics that had personal meaning. Students are encouraged to tell a story to draw people to their question or prompt to make it relevant to them. Giving students the freedom to use their creativity made the activity more engaging and enjoyable (Ruhl, 2015) as well as allowed them internalize the concepts for deeper learning by making meaning of the topic (Merriam and Bierema, 2014).

To prepare students for facilitating their discussion boards, I created a video lesson with best practices for asynchronous facilitation that aligned to the criteria in the rubric and provided examples from the discussion board during week two to highlight student posts that met these criteria. It was my hope that this would further motivate students to use these 
practices in discussion board interaction. I also created an instructional video of a "good" discussion prompt versus a "bad" discussion prompt to provide concrete examples for students. I also showed them how to embed images and links in their post.

Students ended up being quite creative with their discussion prompts. One student used a Star Wars reference to illustrate poor performance. Another student used an example of parenting to talk about a problem-solving process. A few students shared personal stories from work or home that tied to their topic. And a few students posted current event news articles or case studies highlighting their topic in the real world. Most of the students posted memes, gifs and photos to visually enhance their post, which made the posts visually engaging. I provided precise and substantive feedback on each criterion via the embedded rubric in Blackboard early in week four so that students could apply the just-in-time feedback to their final facilitation activity taking place later in the week.

Instead of having students write a final paper on facilitation topics, as the course previously required, I had students facilitate a live synchronous session with their peers to give them real-world facilitation skills. In week one, students signed up for a time to facilitate their synchronous session. Days and times were coordinated for groups of three to four students to take turns facilitating a ten minute Collaborate Ultra session with their peers using the same discussion topic they facilitated in the discussion board in week three.

In the Collaborate Ultra session of week three, students learned tools and strategies to facilitate an engaging synchronous session. I showed students one of the most important resources I use to facilitate - a facilitation guide. This guide includes my script, PowerPoint slides and tools used throughout the session. I gave students access to my facilitation guide and Power Point slides that I used after the session was over and told them they could use them as a template for when they created their own PowerPoint slides and facilitation guides for their sessions.

Together, the class came up with the criteria to be used in the rubric to evaluate their performance as facilitators for the week four assignment. I facilitated this activity using the white board tool in Blackboard Collaborate. Students gave their answers verbally and in the chat and I typed their answers on the white board. Coming up with the criteria together as a class modeled the facilitation of a group decision making process and created more ownership of the assessment criteria from students because they were the ones coming up with the criteria. Students should be part of the rubric development process and have input to strengthen the rubric (Brookhart, 2013). Student-generated assessments can also improve engagement and participation (Grow, 2015). I asked for student volunteers to help me facilitate this process so students could get some formative practice facilitating

\section{Let's create the evaluation criteria together}

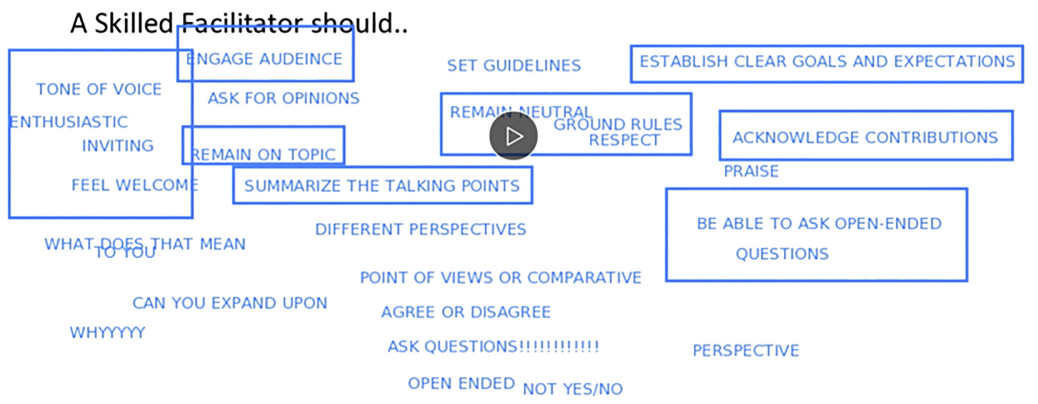


JRIT

14,2

280

synchronously. Two students volunteered and cofacilitated the activity with me. These volunteers asked for suggestions from their peers for the criteria while I scribed their ideas on the white board. Above is a screenshot of the white board brainstorming activity.

The criteria we came up with together were:

(1) Makes everyone feel welcome and heard.

(2) Demonstrate respect for individual/audience needs.

(3) Establish clear goals and expectations.

(4) Engage audience to facilitate group interaction.

(5) Keep session focused.

(6) Summarize main concepts and conclude the session.

One of the student comments that stood out in the exit ticket for the week three synchronous session was as follows: "Highly effective learning session. I am much more skilled on how to manage the Ultra platform and know much more of what facilitation truly is."

To prepare students to facilitate their synchronous session, I gave students access to the PowerPoint slides and facilitation guides I used in the week one and week three synchronous sessions and let students know they were free to use them as a template. I created a short video lesson to help students plan their synchronous sessions. I recommended a format to follow and made suggestions on how to avoid "Death by Power Point". I attended each synchronous session and, overall, was impressed with how well the students facilitated interactive sessions with peers.

Students evaluated their peers using the rubric we came up with as a class and the peer assessment tool in Blackboard. This authentic assessment promoted peer-to-peer teaching, learning and engagement and gave them real world skills in giving and receiving feedback.

Most students gave fair and thoughtful evaluations and provided positive and constructive feedback to their peers. A few students did not give comments to explain their points allocated to peers. Going forward, I will have to make the written feedback portion mandatory and include points for students' feedback.

\section{Results}

Students were given the option of completing a student satisfaction survey in week four. This survey was adapted from Carey Smouse (2017), a client success manager at Blackboard, who created the survey to align with the Blackboard Exemplary Course Program. Eleven out of eighteen students, or about 60 percent, completed the survey. Most of the student respondents agreed $(18.182 \%)$ or strongly agreed $(81.818 \%)$ that they felt the course content was engaging when it was presented in different formats such as videos, case scenarios and exercises. Most student respondents agreed $(45.455 \%)$ or strongly agreed $(54.545 \%)$ that they liked that the course had opportunities for student interaction and collaboration such as discussions and group work. Most student respondents agreed (36.364\%) or strongly agreed $(63.636 \%)$ that the communication activities in the course enhanced their learning and/or built a sense of community among students. Most student respondents agreed $(9.091 \%)$ or strongly agreed (90.909\%) that they were provided a rubric for all assignments and appropriate guidelines indicating how their course participation, performance and interaction would be graded. All student respondents $(100 \%)$ strongly agreed that their instructor took an active role in connecting with students, facilitating and moderating discussions and activities, soliciting participation and providing guidance to students. All student respondents $(100 \%)$ strongly agreed that their instructor provided them with meaningful feedback on activities, assignments and projects. 
Students were asked to define what it means to them to be engaged in a course. Out of the eight respondents who answered, the word participation emerged as a common theme. Five of the eight comments described participating in the live synchronous Blackboard Collaborate sessions. Students were asked if this course met their definition of engaged learning. All of the eight respondents who answered indicated that this course met or exceeded their definition of engaged learning. One student said "sometimes we were overly engaging but I enjoyed all the different ways" (see Appendix for complete survey results).

\section{Discussion}

The results are limited to about $60 \%$ of students who responded to a survey in one class. Preliminary results do indicate that the design of the course and the teaching strategies used contributed to student perception of engagement in an online course. Many more students will need to be surveyed to gather student input on engagement. Nevertheless, this has been an insightful pilot study on the redesign of an online course using adult learning principles and a framework for engaging students.

\section{Conclusion}

This paper described the redesign of an online undergraduate course, ADR410: facilitation fundamentals. This course was redesigned using learner-centered approaches that fit adult students, as follows: practical skills and knowledge they can immediately apply, active learning strategies to encourage participation and involvement in learning, choice and freedom to choose learning paths, constructivist and humanistic methods to make meaning and create community, authentic assessments to evaluate practical knowledge and skills as well as critical thinking and modeling facilitation as a teaching strategy. In addition, the trifecta of engagement framework was used for the design of the course to engage students with course content, with peers and with instructor.

\section{References}

Allen, S. (2016), “Applying adult learning principles to online course design”, Distance Learning, Vol. 13 No. 3, pp. 25-32.

Barkley, E. (2016), Learning Assessment Techniques: A Handbook for College Faculty, Jossey-Bass, San Francisco, CA.

Barrows, H. (1996), "Problem-based learning in medicine and beyond: a brief overview", New Directions for Teaching and Learning, Vol. 68, pp. 3-12.

Barstow Community College (n.d.), BCC Discussion Board Grading Rubric, available at: http:// moodle.bcconline.us/pluginfile.php/59841/mod_resource/content/1/BCC\%20Discussion\%20Board $\% 20$ Grading $\% 20$ Rubric.pdf.

Bart, M. (2018), "Seven ways to facilitate effective online discussions", available at" https:/www. facultyfocus.com/resources/online-learning/course-design-online-learning/seven-ways-facilitateeffective-online-discussions/.

Benassi, V.A., Overson, C.E. and Hakala, C.M. (2014), Applying the Science of Learning in Education: Infusing Psychological Science into the Curriculum, Society for the Teaching of Psychology, available at: http://teachpsych.org/ebooks/asle2014/index.php.

Brame, C.J. (2016). Effective educational videos: principles and guidelines for maximizing student learning from video content, CBE-Life Sciences Education, Vol. 15 No. 4, doi: 10.1187/cbe.1603-0125.

Brookhart, S. (2013), How to Create and Use Rubrics for Formative Assessment and Grading, ASCD, Alexandria, VA.

Butler, S. and McMunn, N.D. (2011), Teacher's Guide to Classroom Assessment: Understanding and Using Assessment to Improve Student Learning, Jossey-Bass, Hoboken, NJ. 
JRIT

14,2

282

Choi, H. and Johnson, S.D. (2005), "The effect of context-based video instruction on learning and motivation in online courses", The American Journal of Distance Education, Vol. 19 No. 4, pp. 215-227.

Davidson, R., Snelling, C., Karanicolas, S., Crotti, T. and Phillips, B. (2019), “Authentic assessment as a tool to bridge the transition between learning and work", in Diver, A. (Ed.), Employability via Higher Education: Sustainability as Scholarship, Springer, New York, NY, pp. 255-274.

Dennen, V. (2007), "Instructor-learner interaction in online courses: the relative perceived importance of particular instructor actions on performance and satisfaction", Distance Education, Vol. 28 No. 1 , pp. 65-79.

Garrison, D. (2000), "Critical inquiry in a text-based environment: computer conferencing in higher education", The Internet and Higher Education, Vol. 2 Nos 2-3, pp. 87-105.

Gokhale, A. and Machina, K. (2018), "Guided online group discussion enhances student critical thinking skills", International Journal of E-Learning, Vol. 17 No. 2, pp. 157-173.

Grow, A. (2015), "Improving student engagement and participation through student-created assessments", in Flores, K.A., Kirstein, K.D., Schieber, C.E. and Olswang, S.G. (Eds), Advances in Exemplary Instruction: Proven Practices in Higher Education, pp. 39-45, available at: http:// repository.cityu.edu/handle/20.500.11803/564.

Hendel-Giller, R.H. (2010), The Neuroscience of Learning: A New Paradigm for Corporate Education, The Martiz Institute White Paper.

Hibbert, M. (2014), "What makes an online instructional video compelling?", available at: https://er. educause.edu/articles/2014/4/what-makes-an-online-instructional-video-compelling.

Iowa State University (n.d.), Ideas to Create a Welcoming, Engaging and Inclusive Classroom, available at: http://www.celt.iastate.edu/teaching/preparing-to-teach/ideas-to-create-a-welcoming-engagingand-inclusive-classroom.

Johnson, S.R. and Stage, F.K. (2018), "Academic engagement and student success: do high impact practices mean higher graduation rates?”, The Journal of Higher Education, Vol. 89 No. 5, pp. 753-781.

King, A. (1993), "From sage on the stage to guide on the side", College Teaching, Vol. 41, pp. 30-35.

Knowles, M. (2005), The Adult Learner: The Difinitive Classic in Adult Education and Human Resource Development, Elsiver, Burlington, MA.

Leslie, H. and McCarty, S. (2018), "Preparing students to facilitate a webinar", in Chen, B., de Noyelles, A. and Thompson, K. (Eds), Teaching Online Pedagogical Repository, University of Central Florida Center for Distributed Learning, Orlando, FL, available at: https://topr.online.ucf.edu/r_ 3nwgranekajkkve/.

Lord, T. (1999), “A comparison between traditional and constructivist teaching environment”, Journal of Environmental Education, Vol. 30 No. 3, pp. 22-27.

Merriam, S. and Bierema, L. (2014), Adult Learning: Linking Theory and Practice, Jossey-Bass, San Francisco, CA.

Momsen, J.L.M. (2010), "Just the facts? Introductory biology courses focus on low-level cognitive skills", CBE Life Sciences Education, Vol. 9 No. 4, pp. 435-440.

Moore, M. (1989), "Three types of interaction”, in Moore, M., Readings in Principles of Distance Education, American Center for the Study of Distance Education, University Park, PA.

National Institute of Education (1984), Involvement in Learning: Realizing the Potential of American Higher Education, US Department of Education, Washington, D.C.

Odena, O. and Burgess, H. (2017), "How doctoral students and graduates describe facilitating experiences and strategies for their thesis writing learning process: a qualitative approach", Studies in Higher Education, Vol. 42 No. 3, pp. 572-590.

Onchengo, N. (2013), Different Types of Learners, [Video file], available at: https://www.youtube.com/ watch? $=3 \_b Q U S F z L I 4 \&$ feature $=$ youtu.be. 
Open2Study (2013), Teaching Adult Learners: Icebreakers, [Video file], available at: https://www. youtube.com/watch?v=nqeKgUSwN_8.

Organization for Economic Co-operation and Development (2015), Skills for Social Progress: The Power of Social and Emotional Skills, OECD, Paris.

Pyke, J. (2010), "A closer look at instructor-student feedback online: a case study analysis of the types and frequency", Journal of Online Learning and Teaching, Vol. 6 No. 1, p. 110.

Rashid, T. and Asghar, H.M. (2016), "Technology use, self-directed learning, student engagement and academic performance: examining the interrelations", Computers in Human Behavior, Vol. 63, pp. 604-612.

Rekrut, M. (1994), “Teaching to learn: strategy utilization through peer tutoring”, High School Journal, Vol. 77 No. 4, pp. 304-314.

Ross-Gordon, J. (2011), "Research on adult learners: supporting the needs of a student population that is no longer nontraditional", Peer Review, Vol. 13, pp. 26-29.

Ruhl, J. (2015), Teaching Methods for Inspiring the Students of the Future, [Video file], available at: $\mathrm{https}: / / \mathrm{www} \cdot$ youtube.com/watch? $\mathrm{v}=\mathrm{UCF}$ g9bcW7Bk.

Rushton, A. (2005), "Formative assessment: a key to deep learning?", Medical Teacher, Vol. 27 No. 6, pp. 509-513.

Sachdeva, A. (1996), "Use of effective feedback to facilitate adult learning", Journal of Cancer Education, Vol. 11 No. 2, pp. 106-118.

Schmidt, N. (2017), Humanizing Online Teaching and Learning: The Quest for Authenticity, available at: https://er.educause.edu/blogs/2017/3/humanizing-online-teaching-and-learning-the-quest-forauthenticity.

Schwartz, R. (2002), The Skilled Facilitator, New and Revised, Jossey-Bass, San Francisco, CA.

Smouse, C. (2017), Blackboard Exemplary Course Survey, available at: https://blackboard.jiveon.com/ community/ecp/blog.

Sturek, T. (2015), "Improvements from a flipped classroom may simply be the fruits of active learning", CBE Life Sciences Education, Vol. 14 Spring, pp. 1-12.

The National Center on Universal Design for Learning (n.d.), What Is UDL?, available at: http://www. udlcenter.org/aboutud1/whatisudl.

van Merrienboer, J. (2001), "ID for competency-based learning: new directions for design, delivery, and diagnosis", Interactive Educational Multimedia, Vol. 3, pp. 12-26. 
JRIT
14,2

284
Appendix

Name Course Satisfaction Survey

Attempts 11 (Total of 11 attempts for this assessment)

Instructions By completing this survey you are agreeing to participate in this study.

Alignments

Question 1: Opinion Scale/Likert

I felt that the course content was engaging when it was presented in different formats such as videos, case scenarios, stories, and exercises.

$\begin{array}{lc} & \text { Percent Answered } \\ \text { Strongly Agree } & 81.818 \% \\ \text { Agree } & 18.182 \% \\ \text { Neither Agree nor Disagree } & 0 \% \\ \text { Disagree } & 0 \% \\ \text { Strongly Disagree } & 0 \% \\ \text { Not Applicable } & 0 \% \\ \text { Unanswered } & 0 \%\end{array}$

Question 2: Opinion Scale/Likert

I liked that this course had opportunities for student interaction and collaboration such as discussions and group work.

$\begin{array}{lc} & \text { Percent Answered } \\ \text { Strongly Agree } & 54.545 \% \\ \text { Agree } & 45.455 \% \\ \text { Neither Agree nor Disagree } & 0 \% \\ \text { Disagree } & 0 \% \\ \text { Strongly Disagree } & 0 \% \\ \text { Not Applicable } & 0 \% \\ \text { Unanswered } & 0 \%\end{array}$

Question 3: Opinion Scale/Likert

The communication activities in this course enhanced my learning and/or built a sense of community among students.

$\begin{array}{lc} & \text { Percent Answered } \\ \text { Strongly Agree } & 63.636 \% \\ \text { Agree } & 36.364 \% \\ \text { Neither Agree nor Disagree } & 0 \% \\ \text { Disagree } & 0 \% \\ \text { Strongly Disagree } & 0 \% \\ \text { Not Applicable } & 0 \% \\ \text { Unanswered } & 0 \%\end{array}$




\section{Question 4: Multiple Choice}

I was provided a rubric for all assignments and appropriate guidelines indicating how my course participation, performance, and interaction would be graded.

Strongly Agree

Agree

Neither Agree nor Disagree

Disagree

Strongly Disagree

Not Applicable

Unanswered
Redesigning an

online course

Percent Answered

90.909\%

$9.091 \%$

$0 \%$

$0 \%$

$0 \%$

\section{Question 5: Multiple Choice}

My instructor took an active role in connecting with students, facilitating and moderating discussions and activities, soliciting participation, and providing guidance to students.

Strongly Agree

Agree

Neither Agree nor Disagree

Disagree

Strongly Disagree

Not Applicable

Unanswered
Percent Answered

$100 \%$

$0 \%$

$0 \%$

$0 \%$

$0 \%$

$0 \%$

$0 \%$

\section{Question 6: Multiple Choice}

My instructor provided me with meaningful feedback on activities, assignments, and projects.

\section{Strongly Agree}

Percent Answered

$100 \%$

Agree

$0 \%$

Neither Agree nor Disagree

Disagree 
JRIT

14,2

286

\section{Question 7: Short Answer}

Define what it means to you to be engaged in a course

Unanswered Responses

Given Answers

An engaged course implements and strives for student participation, both with the professor(s) and among students.

I was paying attention to everything being said, as I knew that we would be asked questions and/or polled soon. Additionally, the expectation of being asked to follow up / elaborate on an answer I provided was high, which further caused me to engage within the course.

I really like all the different ways we have to engage in the class, like blackboard ultra, polling, discussion boards, etc. I feel like we are taking advantage of all the technology we have.

Usually when I feel engaged in a course it is because my instructor is friendly, approachable, available, responsible, positive, and flexible.

Engaged in a course means that I actively participate and interact in the course. That's more than just participating in the Ultra sessions, but also were I am focused on reading the material and seeking out more information to questions I may have.

To be engaged in the course meant participating in the discussion by answering the professor question and giving your opinion on the subject.

It means to answer questions during the lecture, comment on other student's posts, and ask questions when necessary.

The ultra black board enabled us as online students to truely engage. We were able to participate in polls, i felt more comfortable using my microphone to speak my responses, we could also use chat to type out responses if we didnt want to use the microphone. This to me is engaging.

\section{Question 8: Short Answer}

Does this course meet your definition of engaged learning? Please explain why or why not?

Unanswered Responses

Given Answers

Yes, I would say this course was my most engaging course with National University. Many courses usually do not require a weekly meeting at all, or those ones that do have minimal student in

Absolutely. I had never experienced this level of consistent engagement. We where constantly called upon, and or asked to elaborate on questions, answers and/or taking polls.

Yes, absolutely. Again the tools we had access to and the expectation of participation allowed students to feel comfortable and engage more than i feel we ever have. Also Heather was a warm and welcoming instructor and she made it easy and fun to use the tools provided to us.

This course did meet my definition of engaged learning because we had a chance to answer questions making the class interactive. mome

Yes. Professor Leslie is amazing and I appreciate her amazing ability to facilitate in such a positive, upbeat, exemplary manner. She is great.

Yes it does. The lecture was very engaging as the professor frequently asked questions that required us to answer in the chat box. Also, we were required to use or mics and talk. This way the class was not just a monologue, but engaging dialogue.

This course exceeded my expectations of engaged learning. The three Ultra discussions were very interactive and informative. Professor Leslie was very effective in demonstrating course material as well as ensuring that everyone understood the information. I have taken several online courses and this course was the most entertaining, engaging and fun class I have ever taken. I hope my remaining NU classes are just like this one.

Yes, I think sometimes we were overly engaging to try and use all of the options we had but I really enjoy all the different ways we can record, or express our questions to the class. 
Given Answers

The biggest window of clarity l encountered was when facilitation and presentation was explained. That tided the concept of facilitation completely for me.

The professor is very nice and welcoming. You can tell she cares about her job and students. I hope I get to take another class with her!

Blackboard Ultra sessions can be pretty boring, sessions in the class were not. Professor Leslie was fantastic in keeping our attention, interacting with us and keeping us informed. We received several emails a week from her with announcements, content updates and thorough video explanations.

This is my last course at National and my final course to obtain my certification of completion in ADR. I am so grateful this is my final course, Professor Leslie made it a real pleasure.

I truely enjoyed this class. I felt you really needed to pay attention and engage in a way that i never have before. Heather did an amazing job and $i$ hope to be in another one of her classes.

I think this class is great! However, I would recommend an alternative assignment for those who do not wish to give a 10 minute presentation. Many students choose online learning for many different reasons, ranging from personal schedules to not wanting to present in front of classmates.

none

I really like having the option to record ourselves ahead of time, specially because I have time to rehearse what I am saying and not get nervous when I am on the spot.

\section{Question 10: Multiple Choice}

Demographic Variables: Age range

18-24

25-34

35-45

46.55

over 55

Unanswered
Percent Answered

$0 \%$

$63.636 \%$

$36.364 \%$

$0 \%$

$0 \%$

$0 \%$

Question 11: Multiple Choice

Demographic Variables: Gender

Male

Nonbinary

Prefer not to identify

Unanswered

\section{Corresponding author}

Heather J. Leslie can be contacted at: hleslie@sandiego.edu

For instructions on how to order reprints of this article, please visit our website:

www.emeraldgrouppublishing.com/licensing/reprints.htm

Or contact us for further details: permissions@emeraldinsight.com 